\title{
Can Attachment Behaviors Moderate the Influence of Conflict Styles on Relationship Quality?
}

Cameron W. Hee

Brigham Young University

Follow this and additional works at: https://scholarsarchive.byu.edu/etd

Part of the Family, Life Course, and Society Commons

\section{BYU ScholarsArchive Citation}

Hee, Cameron W., "Can Attachment Behaviors Moderate the Influence of Conflict Styles on Relationship Quality?" (2018). Theses and Dissertations. 7302.

https://scholarsarchive.byu.edu/etd/7302

This Thesis is brought to you for free and open access by BYU ScholarsArchive. It has been accepted for inclusion in Theses and Dissertations by an authorized administrator of BYU ScholarsArchive. For more information, please contact ellen_amatangelo@byu.edu. 
Can Attachment Behaviors Moderate the Influence

of Conflict Styles on Relationship Quality?

Cameron W. H. Hee

A thesis submitted to the faculty of

Brigham Young University

in partial fulfillment of the requirements for the degree of

Master of Science

Jonathan G. Sandberg, Chair

Richard B. Miller

Jeremy B. Yorgason

School of Family Life

Brigham Young University

Copyright (C) 2017 Cameron W. H. Hee

All Rights Reserved 


\author{
ABSTRACT \\ Can Attachment Behaviors Moderate the Influence \\ of Conflict Styles on Relationship Quality? \\ Cameron W. H. Hee \\ School of Family Life, BYU \\ Master of Science
}

The purpose of this study was to explore how conflict styles influence relationship quality and how that association is moderated by attachment behaviors in the relationship. The current study uses a sample of married couples $(n=1718)$ who completed the Relationship Evaluation Survey (RELATE). Data was analyzed using an Actor-Partner Independence Model that allows for the testing of moderation. Results indicated that husbands' and wives' conflict style is significantly and positively associated with their own perception of relationship quality, with more extreme styles being associated with decreases in relationship quality. Wives' conflict style was a significant predictor of husbands' relationship quality, but husbands' conflict style was not a significantly associated with wives' marital quality. The model also suggested that an increased frequency of attachment behaviors in romantic relationships is significantly and positively associated with relationship quality for both husband and wives. When assessing for moderating effects, attachment behaviors did moderate the negative relationship between conflict style and relationship quality, for women at the trend level $(\mathrm{P}=.07)$. The clinical applications of these findings are discussed, to provide guidance for clinicians in assisting couples increase attachment behaviors (be more accessible, responsive, and engaged with their partners) to help them offset the negative influence of poor conflict styles.

Keywords: conflict style, attachment behaviors, marital quality 


\section{ACKNOWLEDGEMENTS}

I would like to thank my faculty advisor and chair, Jonathan Sandberg, Ph.D. Thank you for your continual guidance in completing my thesis and for your investment in my personal and professional growth throughout the MFT master's program. I would also like to thank my committee members. Jeremy Yorgason, Ph.D., thank you for helping me gain a better understanding of statistics and for always making yourself available to stop by your office when I had questions. Thank you, Rick Miller, Ph.D., for helping me develop the foundational skills needed to be a better researcher.

I would also like to thank my wife Chloe. I am eternally grateful for your never-ending encouragement, love, and support. You have played an immense role in my success both in and out of school and I am forever grateful for your influence and devotion. 


\section{TABLE OF CONTENTS}

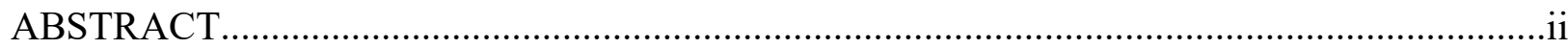

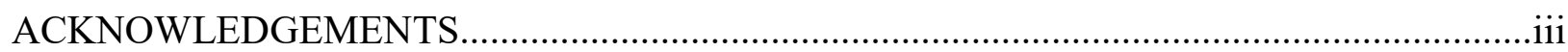

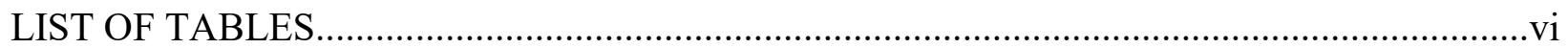

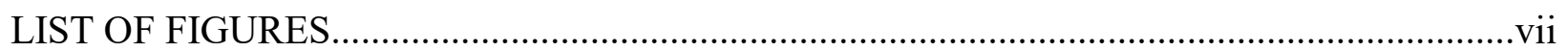

Can Attachment Behaviors Moderate the Influence of Conflict Styles on Relationship

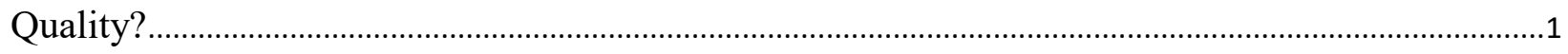

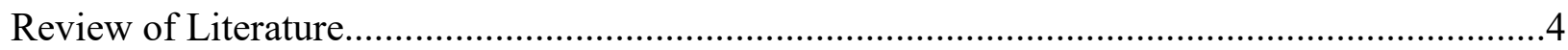

Conflict Styles in Relationships.....................................................................

Attachment and Relationship Quality............................................................6

Attachment, Conflict, and Relationship Quality..................................................

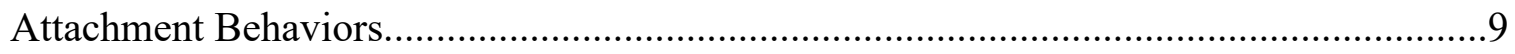

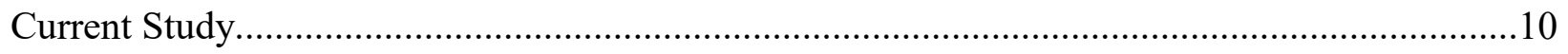

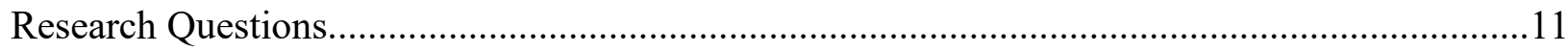

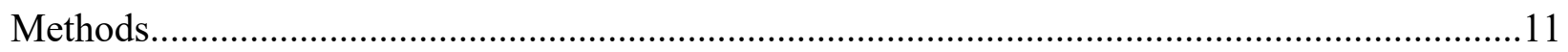

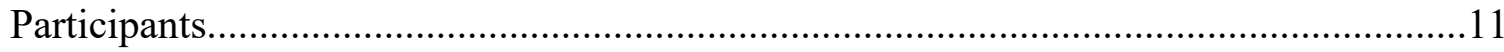

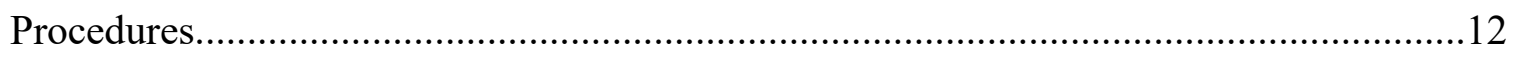

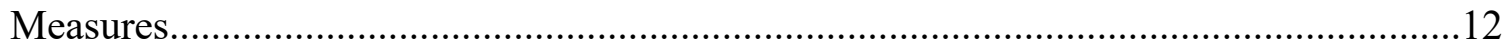

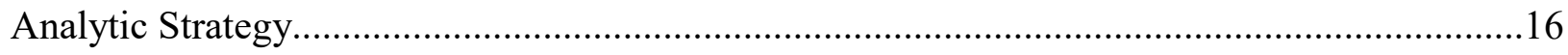

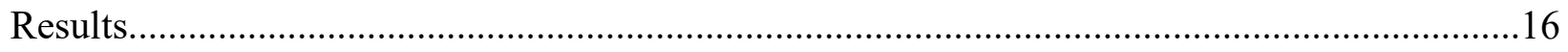

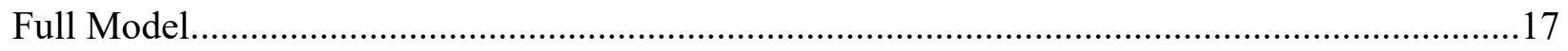

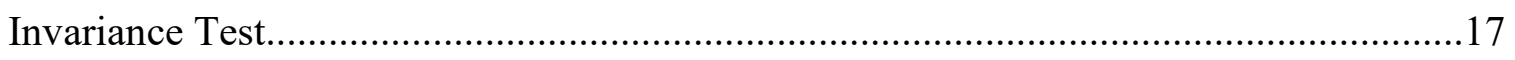

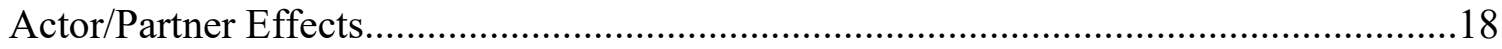


Moderation Effects........................................................................................ 18

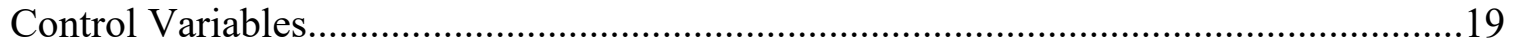

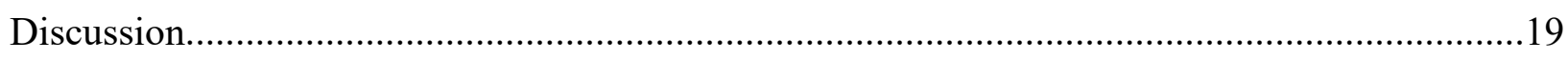

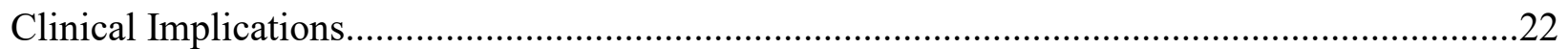

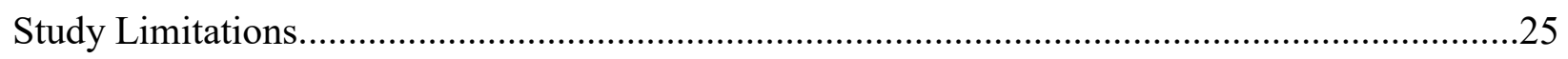

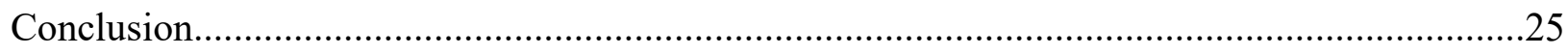

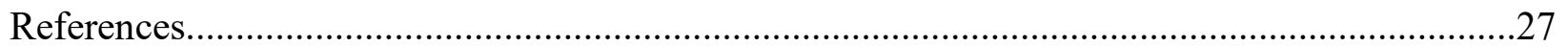




\section{LIST OF TABLES}

Table 1 Descriptive Statistics of Study Variables................................................................41

Table 2 Correlation Table ..................................................................................................42

Table 3 Husband and Wife Marital Quality Factor Loadings.................................................43 


\section{LIST OF FIGURES}

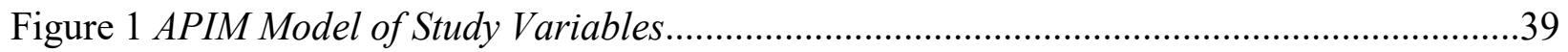

Figure 2 Wife Conflict Style and Attachment Behavior Scores on Marital Quality......................40 


\section{Can Attachment Behaviors Moderate the Influence of Conflict Styles on Relationship Quality?}

There is ample research indicating that couple conflict styles directly affect relationship quality (Finkel, Slotter, Luchies, Walton, \& Gross, 2013; Gottman, 1994; Hanzal \& Segrin, 2009; Ledbetter, 2008; Perrone-McGovern et al., 2014). For example, research on satisfied and dissatisfied couples has shown that couples who demonstrate appropriate conflict styles, such as high levels of compromise and low levels of offense, avoidance, and violence, were able to create an environment that promoted self-disclosure, acceptance of vulnerability, and intimacy in their relationship (Bertoni \& Bodenmann, 2010; Cordova \& Dorian, 2004). These same couples reported higher levels of relational satisfaction when compared to couples who demonstrated higher offense and participated in destructive modalities such as attacking and wounding each other (Bertoni \& Bodenmann, 2010).

In addition, research has shown that conflict style preferences differ amongst individuals, and mismatching styles in couples is common (Gottman, 1999). Couples with mismatched conflict styles have been found to have difficulties overcoming problems due to underlying differences in communication, such as varying degrees of intensity and frequency in persuasion attempts preferred by each partner (Gottman 1993, 1999; Gottman \& Levenson, 2000). Differences in couple conflict styles have also been associated with more stonewalling, relationship problems, less stability, and lower relationship satisfaction in couple relationships, with hostile conflict styles being particularly problematic (Busby \& Holman, 2009). Furthermore, negative conflict styles and unresolved conflict are stronger indicators of marital satisfaction than the conflict or content of problems themselves (Cramer, 2000; Sillars, Roberts, Leonard \& Dun, 2000). 
Consequently, the impact that relational conflict has on romantic relationships appears to be associated with how individuals manage their negative emotions during their interactions (Markman, 1991). For example, destructive patterns of behavior during arguments such as yelling, sarcasm, or hurtful comments, escalate conflict because as partners encounter such behavior, they are inclined to respond in a similar fashion (Crowley, 2008; Kilpatrick, Bissonnette, \& Rusbult, 2002). However, couples that are able to display constructive behaviors through communicating their negative emotions to their partner, as well as be responsive and receptive to their partner's expressed negative emotions, tend to have greater relationship satisfaction (Crowley 2008; Markman, 1991).

It is also important to recognize that conflict is present in every marital relationship, and how individuals handle conflict in their romantic relationships influences their perception of marital quality (Schereen, de Andrade Vieira, Goulart, \& Wagner, 2014). International studies have demonstrated that conflict in marital relationships is common across cultures and have found a positive association between marital quality and positive strategies of conflict resolution (Bisson, 2009; Schereen et al., 2014, Segrin, Hanzal, \& Domschke, 2009; Wheeler, Updegraff, \& Thayer, 2010). Furthermore, couples across cultures report higher levels of relationship satisfaction when spouses adopt targeted strategies to resolve conflict in their relationships. (Segrin et., al 2009; Wheeler et al., 2010). Thus, one of the most vital aspects in the evaluation of relationship quality is an appropriate style of conflict resolution (Hanzal \& Segrin, 2009).

Levels of attachment security are also a key predictor of relationship satisfaction (Seedall \& Wampler, 2013). Findings suggest that greater attachment security is related to positive marital outcomes, while greater attachment insecurity is related to poorer relationship functioning and quality (Feeney, 2016). Attachment styles also influence how individuals shape 
their beliefs surrounding romantic love, trust, availability, as well as how they view their own love-worthiness in relationships (Hazen \& Shaver, 1987). Furthermore, the presence of a secure attachment figure in adulthood, such as a romantic partner, can help produce feelings of security, relief, and contribute to relationship quality. It can buffer the effects of stress in everyday life. The absence of a secure attachment however can lead to distancing or anxious behaviors within relationships (Oka, Sandberg, Bradford, \& Brown, 2014).

Research has demonstrated that there is an association between attachment styles, conflict styles, and relationship quality. For example, one study (Crowley, 2008) found that individuals with secure attachment tend to react to negative partner behavior with constructive behavior to enhance and protect their relationship. In contrast, those who identified as having anxious or avoidant attachment styles were more likely to display deficient conflict management skills and engage in destructive patterns of behavior such as withdrawing from contact and attacking one's partner (Crowley, 2008; Pietromonaco, Greenwood, \& Feldman Barrett, 2004). In addition, Ledbetter (2016) found that individuals with secure attachment styles respond to their partners with positive emotions and behaviors, and engage in more prosocial communication strategies and constructive conflict styles compared to couples with insecure attachment styles. Thus, attachment theory provides the framework to explain how individuals perceive and react to conflict in romantic relationships (Simpson, Rholes, \& Philips, 1996).

There is also a growing body of research that has shown that attachment-specific behaviors also predict couple relationship satisfaction, and may do so more effectively than attachment styles (Sandberg, Bradford, \& Brown, 2015). The key behaviors identified by research that are central to relationship quality and that improve attachment security seem to be accessibility, responsiveness, and engagement (Sandberg, Busby, Johnson, \& Yoshida, 2012). 
Research also suggests that increased levels of attachment behaviors in a romantic relationship promote the safety and security necessary to form long term relationship quality and overcome relationship distress (Mikulincer \& Goodman, 2006; Oka et al., 2014; Sandberg et al., 2015). While the significance of attachment behaviors in relationships is clear, no research has been conducted on how conflict styles impact relationship quality when attachment behaviors are measured in couple relationships. Therefore, the purpose of this study is to examine the effect of conflict styles on relationship quality with attachment behaviors as a moderating variable.

\section{Review of Literature}

\section{Conflict Styles in Relationships}

In an attempt to better understand relationship quality, many researchers have turned their attention to conflict styles. This research has found that conflict is present in most relationships, that resolving conflict increases relationship satisfaction and enhances intimacy, and that difficulties in resolving conflict that arise in unhappy marriages are often due to negative interaction patterns that tend to escalate rather than reduce conflict (Crowley, 2008; Oka et al., 2014; Prager et al., 2015; Scheeren et al., 2014; Watzlawick, Bavelas, \& Jackson, 1967). Furthermore, conflict usually occurs when an individual perceives his or her efforts to meet needs and desires in the relationship as being blocked or interrupted by another (Corcoran \& Mallinckrodt, 2000). Couples also tend to apply both negative and positive communication and interaction patterns they have developed in their relationship during conflict that either contribute to their relationship distress and escalate conflict, or that enhance their relationship quality (Sullaway \& Christensen, 1983). Thus, the experience of conflict itself is not what reduces satisfaction in relationships, rather, it is how couples interact and react to conflict that seems to have a large effect on relationship satisfaction (Gordon \& Chen, 2016; Markman, 1991). Such 
findings, confirm previous research that found negative conflict styles and unresolved conflict to be better predictors of relationship satisfaction than conflict itself (Cramer, 2000).

Specific conflict styles are more detrimental to relationships than others. For example, couples who utilize aggressive or dominating styles characterized by manipulation, inflexibility and rigidity, degrading verbal and nonverbal communication, lack of problem solving skills, and retaliation report low satisfaction and increased conflict in their relationships (Greef \& Bruyne, 2000). Research has also demonstrated that avoiding conflict tends to be associated with low relationship satisfaction (Gottman, 1993). This style is particularly problematic because couples who engage in avoidant conflict styles have difficulty resolving problems which can lead to the resurgence of conflict and emotional distance in relationships (Bisson, 2009; Greef \& Bruyne 2000). In addition, Gottman (1994) found that the presence of criticism, contempt, defensiveness and stonewalling during conflict in relationships are consistent indicators of divorce, with contempt being especially destructive. Although these conflict styles may be occasionally used by happy couples, their habitual use during conflict can create lasting damage in relationships.

Specific conflict styles have also been found to work effectively in happy relationships. For example, Driver, Tabares, Shapiro, and Gottman (2012) found that couples who validate their spouse's emotions, opinion, share mutual respect, keep their voices lower during conflict, and compromise with each other to resolve differences have high levels of marital quality. In addition, volatile couples who tend to be more intense in their disagreements and more passionate maintain satisfaction in their romantic relationships by creating an environment of warmth and love despite their differences. Furthermore, couples who collaborate and compromise with one another tend to have higher levels of relationship satisfaction, greater concern for one another, and are more effective at coming to agreements that satisfy both 
partners (Bisson 2009; Greef \& Bruye, 2000). Busby and Holman (2009) added additional insight to these findings by demonstrating that couples who used a conflict style based on validation had better relationship outcomes than other styles. Such findings are helpful as they demonstrate couples can increase the quality of their romantic relationships as they develop a healthy pattern of addressing conflict.

Research has also examined how conflict styles vary by gender and findings are mixed. For example, studies on the topic suggests that males participate in more competitive conflict styles, while females prefer utilizing conflict styles that consist of compromising and collaborative efforts (Brewer, Mitchell, \& Weber, 2002; Shockley-Zalabak \& Morley, 1984). While other research suggest that male and female conflict style preferences are not influenced by gender but by family structure, culture, stress levels, and specific contextual and situational factors (Bisson, 2009; Callanan, Benzing, \& Perri, 2006; Cingoz-Ulu, \& Lalonde, 2007). Despite varying results in research on gender differences in conflict styles, research findings are unified that conflict styles utilized in couple relations directly impact relationship quality regardless of the conflict stress itself (Cramer, 2000; Sillars, Roberts, Leonard \& Dun, 2000).

\section{Attachment and Relationship Quality}

Attachment theory is used to explain the affectual bond individuals seek with attachment figures throughout their lifespan based on the relationship they developed with their caregiver as an infant (Elkins, 2016; Stakert \& Bursik, 2003). These early life experiences with attachment figures create an internal working model for individuals that shapes their beliefs about expectations of self and others in relationships (Bowby, 1988). Thus, attachment theory helps explain the process by which individuals develop and maintain relationships with others (Collins, 1996). 
Attachment styles refer to the approach an individual takes to create safety in a relationship and are classified as secure or insecure (Holmes, 2014). Individuals' attachment styles are typically defined by their experience with others. For example, attachment security results from one's experience of others as accessible and responsive, while insecure attachment results from one's distressing experience of consistent disconnect from an attachment figure. Research has demonstrated that secure attachment in individuals is positively related to satisfaction in romantic relationships while insecure attachment is a predictor of negative relationship quality (Givertz, Woszidlo, Segrin, \& Knutson, 2013; Sandberg et al., 2015).

Secure attachment predicts relationship quality by influencing how individuals bond with his or her significant other and experience love. For example, Hazen and Shaver (1987) found that securely attached individuals reported that their romantic relationships were happy, friendly and trusting, and have higher proportions of positive emotions than negative ones (Simpson, 1990). These individuals also indicated that they were able to accept and support their partner despite their faults and experience their partner's behavior with greater positivity (Feeney, 2016; Hazen \& Shaver, 1987). Furthermore, research has shown that securely attached individuals tend to have greater confidence in their relationships, as well as in their partners' level of commitment (Mikulincer \& Shaver, 2007). Individuals with insecure attachment styles characterized their love relationships as having emotional highs and lows, fears of intimacy, jealousy, obsessions, and report being overall less satisfied than those with a secure attachment style (Hazen \& Shaver, 1987; Tucker \& Anders, 1999). In addition, insecure or avoidant individuals have been found to be less invested in their relationships, to seek emotional and psychologically distance from their partner, and are more likely to engage in infidelity (Campbell \& Marshall, 2011; DeWall et al., 2011). 


\section{Attachment, Conflict, and Relationship Quality}

Recognizing the important role attachment theory and conflict styles play in relationship quality, a substantial amount of research has examined how these variables influence one another. (Ledbetter, 2016; Liu, Cui, \& Han 2014; Scheeren et al., 2014; Simpson et al., 1996). For example, recent evidence has demonstrated that the type of conflict styles utilized by individuals directly impacts how couples feel about their relationship regardless of the attachment styles present in the relationship (Scheeren et al., 2014). In addition, a study that examined the association of attachment, conflict style, and relationship satisfaction in 207 married individuals found that individuals' feelings of self-worth and partner availability are related to levels of accommodation in their marriage. This same study also found that securely attached individuals participated in behaviors that protected their relationship and demonstrated a desire to comfort, trust, and be open with their partner in response to a partner's destructive behavior. (Crowley, 2008; Gaines et al., 1997). Securely attached individuals are also more likely to be active problem solvers, better at compromising, more integrative, and adopt conflict resolutions behaviors that satisfy both parties' concerns (Shi, 2003).

In contrast, individuals who are anxious or avoidantly attached exhibit deficient conflict management skills and frequently engage in destructive patterns of behaviors such as attacking and withdrawing from their partner (Crowley, 2008). In addition, research has also demonstrated that individuals who are securely attached utilized mutually focused conflict strategies, while individuals who are avoidant and anxiously attached have difficulty compromising during conflict as it requires their attention to shift from preoccupation towards a partner to focus on the stressor or desired goal (Pistole, 1989). Furthermore, research has found that there is a correlation between attachment style, conflict style and physical violence present in married 
couples. (Bond, \& Bond, 2004). For example, a study done by Stith, McCollum, and Rosen (2011) found that insecurely attached partners are more likely to use violence in an attempt to engage or push partners away, which has the potential to result in partners responding back in turn with violence. Such couples not only report higher levels of relational aggression but also seem to use insecure attachment language to describe their relationship (Goldstein, Chesir-Teran, \& McFaul, 2008; Wilson, 2011). Moreover, insecure attachment styles are related to partners' use of aggression for both males and females, with males tending to be more physically aggressive and females tending to be more relationally aggressive (Oka et al., 2014).

\section{Attachment Behaviors}

Attachment behaviors are defined as behaviors that increase attachment security and emotional proximity to a preferred individual (Holmes, 2014). Research has identified accessibility, responsiveness, and engagement as key attachment behaviors that influence closeness and form strong attachment bonds in relationships (Sandberg et al., 2012). Research has also indicated that attachment behaviors not only promote closeness in relationships but may be vital for the creation of attachment security in adult relationships, and effect the styles of attachment individuals have (Mikulincer \& Goodman, 2006; Sandberg et al., 2015).

Although there is ample research indicating the important role attachment styles play in relationship quality, a recent focus on attachment specific behaviors has demonstrated that attachment behaviors may predict relationship quality better than attachment styles (Sandberg et al., 2015). Attachment behaviors have been found to mediate negative relationship adversities, predict health behaviors, marital stability, and promote positive communication (Davis, Sandberg, Bradford, \& Larson, 2016; Knapp et al., 2015; Oka et al., 2014; Sandberg et al., 2015). Despite these results, no study has included attachment behaviors to determine how this 
variable may impact conflict styles as past literature has primarily focused on the influence styles have on satisfaction (Crowley, 2008; Can, Norman, Welbourne, \& Calhoun, 2008; Shi, 2003). Thus, research showing the role attachment specific behaviors may have on relationship quality with the presence of extreme and moderate conflict styles remains untested.

It may be that secure attachment behaviors could serve to moderate the negative influence of poor conflict styles on marital quality. In previous research on attachment behaviors and relationship outcomes, a number of authors have noted that certain aspects of couple functioning (relationship self-regulation and time spent together) may differ for partners who have high levels of attachment promoting behaviors and those who have low levels (Dobry, Bradford, Sandberg, \& Coyne, under review; Drean, Bradford, Sandberg, \& Johnson, under review). The same process may be true in the study of the association between conflict styles and relationship quality; this statistical relationship may differ for couples based on level of attachment behaviors.

\section{Current Study}

Therefore, one major purpose of this study is to determine if attachment behaviors can moderate the negative association between adverse conflict styles and marital quality. In addition, the current study will extend existing literature to consider both actor and partner effects in the study of conflict styles and relationship satisfaction. In addition to testing for both actor and partner effects, we will also consider if these patterns and associations differ by gender, as previous research suggests maybe the case (Bisson, 2010; Mackey, \& O'Brien, 1998; Wanic, $\&$ Kulik, 2011). Finally, we are also interested in the potential moderating influence of attachment on the relationship between conflict style and relationship quality due to previous 
findings that attachment behaviors do moderate some relationships were marital quality is the primary outcome (Dobry et al., under review).

\section{Research Questions}

Drawing upon the previous review of literature, this study will attempt to answer the following four research questions in the current study:

1. Does one's own conflict style predict relationship quality for both husbands and wives (actor effects) and does conflict style of one partner predict marital quality for the other (partner effects)?

2. Does one's own attachment behaviors predict relationship quality for both husbands and wives (actor effects) and does attachment behaviors of one partner predict marital quality for the other (partner effects)?

3. Do attachment behaviors moderate the relationship between conflict styles and relationships quality for both the actor and the partner?

4. Do these relationships differ by gender?

\section{Methods}

\section{Participants}

The current study used a sample of married heterosexual couples $(n=1718)$ who completed the RELATE survey between the years 2011 and 2014. The data was paired for couples that were married. On average females were 32 years old and males were 34 years old, with $94 \%$ of males and $98 \%$ of females reporting completion of or participation in college education. Male racial demographics included 84\% white, 5\% black, 2\% Asian, 5\% Latino, 1\% Native American, 2\% mixed/biracial, and 1\% as other. Female demographics included 83\% white, 4\% black, 3\% Asian, 5\% Latino, 1\% Native American, 2\% mixed/biracial, and 2\% as 
other. The majority of males (78\%) and females (79\%) listed a Christian affiliation (Catholic, Protestant, or LDS), followed by no religion ( $13 \%$ male, $12 \%$ female), other religion ( $5 \%$ male, $5 \%$ female), and Jewish ( $2 \%$ male, $2 \%$ female).

\section{Procedures}

Data from this study came from the larger RELATE data set (Busby, Holman, \& Taniguchi, 2001). The RELATE survey is an online questionnaire that had over 300 items at the time of the study which were pulled from established measures or created for the study. RELATE is offered to individuals both in relationships and those who are not and examines contextual, relationship, and individual variables that identify strengths and weaknesses within current and potential future relationships. Participants are referred to RELATE through a variety of means including mental health professionals, family, friends, educators, clergy, or through online ads or printed advertisements. The RELATE questionnaire has demonstrated its reliability through repeated validity testing, and by showing test-retest and internal consistent reliability and content (Busby et al., 2001).

\section{Measures}

Control variables. The following control variables were selected due to their theoretical connection to relationship quality and conflict style. Information on clients' income (ranging from under $\$ 20,000$ - $\$ 300,000$ or above) were taken from the demographics portion of the RELATE survey and data on participants' length of marriage (ranging from 0 to 3 months - over 40 years) was gathered from the Relationship Status section of the RELATE survey. All control variable data was self-reported by RELATE survey participants.

Attachment Behaviors. Attachment behaviors in this study were measured by the Brief Accessibility, Responsiveness, and Engagement (BARE) Scale which was added to RELATE in 
2011 (Sandberg, et al., 2012). The BARE assessment measures key attachment system behaviors in couple relationships through three sub-scales: accessibility, responsiveness, and engagement. Each sub-scale includes two items and participants respond to questions using a 5-point Likert scale from 1 (Never True) to 5 (Always True). Examples of individual items on the BARE include: "I am rarely available to my partner" (accessibility), "I listen when my partner shares her/his deepest feelings" (responsiveness), and "It is hard for me to confide in my partner" (engagement). The Cronbach's Alpha in this study for both males and females was .82. For this study, the partner scores were reported as it has been a more effective measure in previous studies (Bradford, Novak, Sandberg, \& Busby, 2017).

Conflict style. The current study used the Relationship Aggression sub-scale in the RELATE data to analyze the conflict styles of participants. The sub-scale was based on items presented by Holman and Jarvis (2003) to report how couples' conflict styles aligned with Gottman's Four Conflict Styles (Avoidant, Validating, Volatile, and Hostile). These items were found to be a valid measure of the Gottman types and were used to accurately predict the stability and satisfaction of relationships, and whether or not these relationships had low levels of criticism, contempt, and flooding as predicted by the Gottman model (Holman \& Jarvis, 2003; Busby \& Holman, 2009). Each item was then adapted so that individuals taking the RELATE survey would be able to rate their individual style of conflict (Busby \& Holman, 2009). The Relationship Aggression sub-scale assesses individuals' perceptions of self and conflict styles and was used to measure this specific variable in this study. It consists of four common ways individuals handle disagreements and or react to conflict in relationships:

1. I avoid conflict. I don't think there is much to be gained from getting openly angry with others. In fact, a lot of talking about emotions and difficult issues seems to make matters 
worse. I think that if you just relax about problems, they will have a way of working themselves out.

2. I discuss difficult issues but it is important to display a lot of self-control and to remain calm. I prefer to let others know that their opinions and emotions are valued even if they are different than mine. When arguing, I try to spend a lot of time validating others as well as trying to find a compromise.

3. I debate and argue about issues until they are resolved. Arguing openly and strongly doesn't bother me because this is how differences are resolved. Although sometimes my arguing is intense that is okay because I try to balance this with kind and loving expressions. I think my passion and zest actually leads to a better relationship with lots of intensity, making up, laughing, and affection.

4. I can get pretty upset when I argue. When I am upset at times I insult others by using something like sarcasm or put downs. During intense discussions I find it difficult to listen to what others are saying because I am trying to make my point. Sometimes I have intensely negative feelings toward others when we have a conflict.

Participants were asked to mark an " $\mathrm{X}$ " next to the item that best describes how they usually handle conflict. Items 1 and 4 were combined to group participants who have more extreme (avoidant/hostile) conflict styles, while items 2 and 3 were combined to group participants who have a more measured style of handling conflict. Thus, the analysis proceeded with a dichotomous variable for conflict style, extreme vs moderate. This approach was taken based upon literature that describes healthy styles as more moderate and unhealthy conflict styles as more extreme (Driver et al., 2012; Gottman, 1993; Gottman; 1994; Greef \& Bruyne, 2000). 
Relationship quality latent variable. The relationship quality latent variable was comprised of three different subscales from the RELATE measure; Marital Problems, Marital Satisfaction, and Marital Stability.

The Problems areas subscale is a 15-item assessment that measures common problem areas for marriage with higher scores indicating more problems. The Problem Areas subscale utilizes a 5-point scale ranging from 1 (Never) to 5 (Very Often). Specific examples of items on the scale include: "Financial matters", "Intimacy/Sexuality", "Who's in charge", and “Communication”. The Cronbach's Alpha for the Problem Areas subscale was .82 for females and .81 for males.

Marital stability was assessed using the Relationship Stability Scale which is a 3-item measure that also incorporates a 5-point scale ranging from 1 (Never) to 5 (Very Often), with higher scores indicating greater relationship instability. Examples of items on the subscale include: "How often have you thought your relationship or marriage might be in trouble" and "How often have you broken up or separated and then gotten back together". The Cronbach's Alpha for this subscale was .79 for females and .77 for males.

Relationship satisfaction was measured using the Relationship Satisfaction scale included in the RELATE measure (Busby \& Holman, 2009). The Relationship Satisfaction scale is a 7item scale, that utilizes a 5-point Likert scale ranging from 1 (Very Dissatisfied) to 5 (Very Satisfied), with higher scores indicating greater satisfaction. The Relationship Satisfaction scale specifically assesses participant's satisfactions in areas such as time spent together, intimacy, and communication. Examples of specific items rated by participants on the Relationship Satisfaction scale include: "The amount of time you have together", "Your overall relationship with your partner", "The love you experience", "The relationship equality you experience", and "The 
quality of your communication". The Cronbach's Alpha in the Relationship Satisfaction subscale was .88 for males and .89 for females.

\section{Analytic Strategy}

The AMOS statistical software package was used to analyze the data for this project using an Actor-Partner Independence Model (APIM; Kashy \& Kenny, 2000; AMOS; Kline, 2005). This approach was selected because when analyzing dyadic data, the variables of one partner can be correlated to the variables of another, referred to as non-independence in research literature (Whittenborn, Dolbin-MacNab, \& Keiley, 2013). The APIM allows a researcher to approach the data at two levels (individual and couple) and deals with issues regarding nonindependence by analyzing actor effects (e.g., the effect of the participant's behaviors on his/her own outcomes) and partner effects (e.g., the effect of the spouse's behaviors on her/his own outcomes, and vice versa) in the same model. The APIM also allows for the testing of mediation or moderation, a tool that is helpful for therapists seeking to understand how and why relationships change (Bartle-Haring, McWey, \& Durtschi, 2014). To interpret the moderation analysis, interaction terms that are significant were plotted to illustrate moderation effects.

For this study, conflict style is the predictor variable and relationship quality is the outcome variable. Attachment behaviors are conceptualized as a potential moderating variable. To test for moderation, an interaction term will be created with conflict style and attachment behaviors. Length of marriage (LM), religion (R), and income (I) will be added as control variables because of their relevance to marital quality. (See figure 1)

\section{Results}

Results from the descriptive statistics show that the sample was drawn from a population of couples that reported general satisfaction with their relationship, typical displays of 
attachment behavior, and moderate conflict styles (See Table 1). Results from a bivariate correlation analysis showed appropriate associations between key variables in the expected direction and in harmony with previous research (see Table 2).

\section{Full Model}

In order to test the goodness of fit between the model and the data, we relied upon the following goodness of fit statistics: chi-square $\left(\chi^{2}\right)$, the comparative fit index (CFI), TuckerLewis Index (TLI), the root mean square error approximation (RMSEA; Hu \& Bentler, 1999). According to these established criteria, the model fit for this study was acceptable $\left(\chi^{2}=\right.$ $180.88, \mathrm{df}=39, p<.001, \mathrm{CFI}=.969, \mathrm{TLI}=.928, \mathrm{RMSEA}=.079)$. For the men, $78 \%$ of the variance in marital quality was explained by the variables in the model, with $82 \%$ explained by the variables for the women.

\section{Invariance Test}

We tested for measurement invariance across husbands and wives for marital quality. When factor loadings were constrained to be equal, model fit did not worsen (Chi Square Difference $=1.069, \mathrm{df}=2, p=.586 ;$ Merideth $\&$ Teresi, 2006). When intercepts of marital quality items were constrained to be equal across husbands and wives, model fit significantly worsened (Chi Square Difference $=13.430, \mathrm{df}=3, p<.01)$. Therefore, weak measurement invariance was established, as the items load similarly on marital quality for husbands and wives.

We tested for structural invariance across husbands and wives involving regression paths between conflict style and attachment behaviors and marital quality in the model. Constraining regression paths for husbands to be equal to regression paths for wives significantly worsened model fit (Chi Square Difference $=10.089, \mathrm{df}=4, p=.039$ ). Thus, the final model had factor loadings constrained to be equal across husbands and wives, but regressions paths were allowed 
to be estimated freely.

\section{Actor/Partner Effects}

The APIM model was used to test for the influence of conflict style and attachment behaviors on relationship quality (see figure 1). In the model, female conflict style was significantly and positively associated with female marital quality $(\beta=.09, p<.01, S E=.03)$, and was also significantly and positively associated with male marital quality at trend level $(\beta=$ $.05, p=.07, S E=.03)$. These results suggest that for women and men (at trend level) in the study, a more moderate conflict style among females is related to higher relationship quality. Male conflict style was significantly and positively associated with his own marital quality $(\beta=$ $.08, p=.001, S E=.03)$, but was not associated with wives' marital quality $(\beta=.03, p>.10, S E=$ $.03)$, suggesting that a more moderate conflict style among males is related to higher relationship quality for him, but not for her.

Also in the model, female attachment behaviors (as reported by husbands) were significantly and positively associated with wives' marital quality $(\beta=.69, \mathrm{p}<.001, \mathrm{SE}=.003)$, and with husbands' marital quality $(\beta=.31, \mathrm{p}<.001, \mathrm{SE}=.003)$. These results suggest that for women and men in the study, higher levels of attachment behaviors by women are related to increased reports of marital quality for men and women. Husband attachment behaviors (as reported by wives) were significantly and positively associated with his own marital quality $(\beta=$ $.6, \mathrm{p}<.001, \mathrm{SE}=.004)$, and also with wives' marital quality $(\beta=.21, \mathrm{p}<.001, \mathrm{SE}=.003)$, suggesting that higher attachment behaviors among husbands is related to higher relationship quality for husbands and wives.

\section{Moderation Effects}

When the interaction term was created (conflict style $\mathrm{x}$ attachment behaviors) for both 
women and men, and was included in the model, only the association between the female interaction term and her marital quality was significant (at trend level) $((\beta=.05, \mathrm{p}=.071, \mathrm{SE}=$ .005). No other interaction terms, for either gender, were significantly associated with marital quality. This suggests that for the women in the study, reports of her attachment behaviors moderated the influence of conflict styles on marital quality. This moderation effect was further probed by plotting the data. Graphic results suggest that for wives with high attachment behaviors and extreme conflict styles scored higher on marital quality and wives with lower attachment behaviors, regardless of conflict style, reported lower marital quality (See Figure 2).

\section{Control variables}

As mentioned previously, income and length of marriage were included in the analysis as control variables. Only length of marriage was significantly associated with marital quality, suggesting that as length of relationship increases marital quality declines for both women (quality $(\beta=-.09, \mathrm{p}<.001, \mathrm{SE}=.005)$ and men $(\beta=-.09, \mathrm{p}<.01, \mathrm{SE}=.004)$ in the study.

\section{Discussion}

\section{Research Question Findings}

Question one. The results of this study concerning conflict style and relationship quality confirm previous research findings that demonstrate the negative impact adverse conflict styles have on relationship quality (Gordon \& Chen, 2016; Gottman, 1993; Markman, 1991; Scheeren et al., 2014; Sullaway \& Christensen, 1983). Specific to the results from the APIM model used in this study, the use of extreme styles of conflict in marriage is significantly associated with poorer reported relationship quality for both men and women. This may be because individuals who utilize aversive conflict styles are less likely to acknowledge their role in problems, evaluate their own behaviors, be less accommodating and willing to make changes, and are less focused 
on the needs of their partner (Bisson, 2009; Halford 2011; Johnson \& Greenman, 2006; Pistole, 1989).

Furthermore, individuals who demonstrate aversive conflict styles may also experience more frequent negative interactions with their romantic partner, which may interfere with or prevent couples from demonstrating behaviors that help develop a secure relationship bond due to the emotional distance and stress conflict causes (Gottman, 1993; Greef \& Bruyne, 2000). It is important for clinicians to recognize that although conflict is common for couples who present for therapy, certain types of conflict (Avoidant, Hostile) are more detrimental than others and the mere presence of conflict does not necessarily cause relational distress (Cramer, 2000).

Question two. In addition, the findings suggest wives' use of unhealthy conflict styles influences husbands' (at trend level) relationship quality, but not vice versa. This finding confirms previous research that highlights gender differences in conflict styles and how those styles influence relationship quality (Bertoni \& Bodenmann, 2010; Crowley, 2008; Gottman, 1993; Markman, 1991; Worely \& Samp, 2016).

One potential explanation for the gender differences in the partner effects might be related to increased relational awareness women tend to demonstrate in their romantic relationships. This increased relational attunement may lead to wives be less dependent on their husbands' verbal input and behaviors to determine the strength and quality of their relationship (Acitelli, 1992). This suggests that husbands may be less adept at forming and maintaining a perception of relationship quality independent from the behaviors he observes from his wife (Acitelli, 1992). Somehow for the women in this study their perception of relationship quality is not associated with conflict style in the same way his is influenced by hers. Clinicians may wish to be particularly sensitive to this gender based finding and assess for ways that his more extreme 
conflict style may be tolerated at unhealthy levels. It is also important to remember that these gender based findings were only significant at the trend level, and future research is needed to fully establish the findings; therefore the above discussion should be interpreted cautiously.

Question three. In this study, the men and women who self-reported higher attachment behaviors were found to have greater relationship quality. Furthermore, for women, attachment behaviors moderated the relationship between their own conflict style and relationship quality at trend level, but not for men.

This finding confirms previous research findings that help illustrate how attachment behaviors may influence romantic relationships. For example, the perception of attachment behaviors in relationships has been shown to increase emotional closeness, buffer the impact of relationship adversities, and help individuals perceive their partner as a source of safety, setting the foundation to promote lasting satisfying relationships (Oka et al., 2014; Sandberg et al., 2015). It may be that the women in the sample who reported higher levels of attachment behavior are better able to cope with the negative influence of unhealthy conflict styles. It appears that higher levels of attachment behaviors trend towards buffering the negative influence of conflict style on relationship quality.

It is also important to note the gender differences in the moderating effect of attachment behaviors in the relationship between conflict styles and marital quality. The trend level findings were significant only for women. These results provide insight to previous research that suggests that wives who report fewer attachment behaviors may perceive themselves as less attached to their husband and have lower relationship satisfaction (Patrick, Knee, \& Canevello, 2007). Previous research has shown women are more likely to initiate attachment behaviors in relationships than men, put a greater emphasis on others and their needs, have a greater sense 
relationship awareness, be more capable discerning their spouse's emotions, and are more effective at nurturing relationships (Acitelli, 1992; Christov-Moore, Simpson, Coudé, Grigaityte, Iacoboni, \& Ferrari, 2014). This difference in relationship attentiveness and awareness may mean that women are more likely to initiate connection and even repair in their relationship when compared to males through the implementation of attachment behaviors, as a natural response to conflict. These findings may explain how increased levels of attachment behaviors seem to moderate the relationship between conflict style and marital quality for women only.

Furthermore, previous research has shown that due to masculine gender roles, men typically have a harder time expressing emotions when compared to women, and often shutdown and withdraw from their partner during conflict (Windle \& Smith, 2009). Moreover, men tend to focus on problem solving, performance, and sex as a means to maintain the quality of their relationships (Greenman, Faller, \& Johnson, 2012). Thus, husbands may be less inclined to initiate the use of attachment focused behaviors when compared to their wives during daily interactions. These studies help shed light on why the moderation effect trended toward significance for women but not men.

\section{Clinical Implications}

The findings from this study provide insight to therapists working with married couples in at least two ways. First, extreme styles of conflict management negatively impact couples' relationship quality. Therefore, clinicians working with couples to improve their overall relationship quality may want to assess the type of conflict styles each spouse uses with one another.

In addition, clinicians may want to provide direct feedback to help both husbands and wives identify the behaviors they turn to most often in times of conflict, and to help spouses 
understand how these behaviors influence the other. This is especially important due to potential differences in spouses' relational awareness, as well as the frequency in which husbands and wives overlook and minimize their role in, and the severity of, conflict in their relationships (Acitelli, 1992; Henning, Jones, \& Holdford, 2005). Due to these previous findings, we suggest that clinicians be thorough in their assessment of conflict style, and integrate the perspective of each partner (both self and other) to increase awareness of each spouses' needs and approach to handling disagreements (Gottman, 1999).

Second, our findings suggest that helping couples increase the frequency in which they demonstrate attachment behaviors in their romantic relationship can improve both spouses' perceived marital quality, and in particular may even help wives feel closer to their husband despite the conflict style used in the relationship. The results from our analyses also indicate a correlation between increased marital quality for hyper-engaged couples where conflict styles are extreme, and attachment behaviors are high, which suggests a moderating effect. Moreover, couples who had lower reported attachment behavior scores also had lower marital quality despite the type of conflict style they used. Thus, clinicians working with distressed couples to improve their marital quality should not only focus on conflict de-escalation but also help couples increase attachment behaviors in their relationship.

Furthermore, clinicians who help spouses focus on attachment behaviors (accessibility, responsiveness, and engagement) during treatment may also help couples improve their attachment bond (Sandberg et al., 2015). Clinicians can also utilize assessments such as the BARE (Sandberg et al., 2012) to track clients' changes in attachment behaviors during treatment. This tool can be used in session to help spouses identify patterns of behavior when reacting to 
conflict, find ways to meet one another's attachment needs, increase relational awareness, and to assist couples in creating an environment that fosters safety and support.

Two clinical approaches that therapists may find useful when working with couples who utilize unhealthy conflict styles are EFT and the Gottman model. In EFT, one of the primary goals of the model is to help the pursuing spouse soften and to assist the withdrawn spouse to engage (Furrow, Edwards, Choi, \& Bradley, 2012). Clients' negative behaviors that manifest themselves during conflict could be reframed as attempts to meet attachment needs, and new experiences in session can be created to help strengthen couples' romantic attachment bonds. As treatment is implemented successfully and spouses are able to meet one another's attachment needs, couples' emotional connection improves, dysfunctional behaviors decrease, and spouses become more aware of their own personal experiences and emotions (Johnson, 2004).

The Gottman model may be particularly helpful in assisting couples address conflict because one of the model's primary goals is to increase a dyad's ability to repair after conflict. This focus on repair mechanisms is vital due to the fact that all couples, regardless of their level of marital satisfaction, deal with conflict or the "tasks" of being married that interfere with healthy patterns of communication (Gottman, 1999). Thus, Gottman therapists work to coach unhappy couples to develop the skills they need to eliminate relationally destructive behaviors that predict conflict and divorce such as contempt, criticism, stonewalling, and defensiveness. Gottman therapists also help couples improve marital friendship by assisting clients in reducing negative affect during conflict and to develop the skills required to increase their positive interactions with each other (Gottman, 1999). While focusing on clients' marital friendship, clinicians may want to look for opportunities to coach clients in implementing attachment behaviors as an additional resource to strengthen the marital bond. 


\section{Study Limitations}

In this study, there were several limitations that need to be addressed. First, the sample came from the RELATE questionnaire and participants primarily consisted of couples who have paid a fee to gain insight to determine the strengths and weaknesses in their marriage. Thus, the population used in this study likely does not consist of a clinically distressed population that are experiencing high conflict. Furthermore, the majority of the participants in this study selfreported as Caucasian, religious, and college educated, which makes it difficult to generalize this study's findings due to a lack of appropriate ethnic and socio-economic representation. Therefore, future researchers may want to investigate a similar model, with a population that includes a more diverse and clinically distressed sample to determine if the findings apply to other populations.

Second, because the data is cross sectional, it is difficult to determine how the findings might differ for couples across marriage. In addition, the quantitative nature of the data makes it impossible to understand the meaning couples ascribe to conflict or how they feel the conflict influences the nuanced and subjective aspects of their relationship. Therefore, future researchers may want to consider using qualitative approaches to gather data that is more sensitive to couples' experiences as they use unhealthy styles of conflict management with their spouse. Lastly, future researchers may also want to participate in longitudinal data collection to see how the conflict styles and attachment behaviors impact couple relationships quality over time.

\section{Conclusion}

This study examined attachment behaviors as a moderating variable between conflict style and relationship quality for heterosexual married couples. The model utilized in the present study suggests there is a positive relationship between the use of moderate conflict styles and 
relationship quality for both men and women, and that an increased frequency in reports of attachment behaviors can also help couples experience greater quality in their romantic relationships, especially for women. These findings provide important clinical insight and add to a growing body of research that highlights the important role attachment behaviors play in the relationship quality couples experience. 


\section{References}

Acitelli, L. K. (1992). Gender differences in relationship awareness and marital satisfaction among young married couples. Personality and Social Psychology Bulletin, 18(1), 102110. doi:10.1177/0146167292181015

Bartle-Haring, S., McWey, L. M., \& Durtschi, J. A. (2014). Dyadic or systemic data analysis. In R. B. Miller \& L. N. Johnson (Eds.), Advanced Methods in Family Therapy Research: A Focus on Validity and Change (pp. 366-382). New York, NY, US: Routledge/Taylor \& Francis Group.

Bertoni, A., \& Bodenmann, G. (2010). Satisfied and dissatisfied couples: Positive and negative dimensions, conflict styles, and relationships with family of origin. European Psychologist, 15(3), 175-184. doi:10.1027/1016-9040/a000015.

Bisson, M. A. (2010). An examination of conflict styles during stressful conflicts and their relationship to marital satisfaction. Dissertation Abstracts International Section A, 70, 4117.

Bond, S. B., \& Bond, M. (2004). Attachment styles and violence within couples. Journal of Nervous and Mental Disease, 192(12), 857-863. doi:10.1097/01.nmd.0000146879.33957.ec.

Bowlby, J. (1988). A secure base: Parent-child attachment and healthy human development. New York, NY: Basic Books.

Bradford, A. B., Novak, J., Sandberg, J., \& Busby, D. (2017). It's all a matter of perception: Testing actor and partner effects of perceived self-and other attachment on relationship quality. Manuscript in Preparation. 
Brewer, N., Mitchell, P., \& Weber, N. (2002). Gender role, organizational status, and conflict management styles. International Journal of Conflict Management, 13, 78-94.

Busby, D. M., \& Holman, T. B. (2009). Perceived match or mismatch on the Gottman conflict styles: Associations with relationship outcome variables. Family Process, 48(4), 531-545. doi:10.1111/j.1545-5300.2009.01300.x.

Busby, D. M., Holman, T. B., \& Taniguchi, N. (2001). RELATE: Relationship evaluation of the individual, family, cultural, and couple context. Family Relations, 54, 308-316.

Callanan, G. A., Benzing, C. D., \& Perri, D. F. (2006). Choice of conflict-handling strategy: A matter of context. Journal of Psychology, 140, 269-288.

Campbell, L., \& Marshall, T. (2011). Anxious attachment and relationship processes: An interactionist perspective. Journal of Personality, 79(6), 917-947. doi:10.1111/j.14676494.2011.00723.x.

Cann, A., Norman, M. A., Welbourne, J. L., \& Calhoun, L. G. (2008). Attachment styles, conflict styles and humour styles: Interrelationships and associations with relationship satisfaction. European Journal of Personality, 22(2), 131-146. doi:10.1002/per.666.

Cingoz-Ulu, B., \& Lalonde, R. N. (2007). The role of culture and relational context in interpersonal conflict: Do Turks and Canadians use different conflict management strategies? International Journal of Intercultural Relations, 31, 443-458.

Collins, N. (1996). Working models of attachment: Implications for explanation, emotion, and behavior. Journal of Personality and Social Psychology, 71(4), 810-832.

Corcoran, K., \& Mallinckrodt, B. (2000). Adult attachment, self-efficacy, perspective taking, and conflict resolution. Journal of Counseling \& Development, 78, 473- 483. 
Cordova, J. V., \& Dorian, M. (2004). Coding intimacy in couples' interactions. In P. K. Kerig \& D. Baucom (Eds.), Couple observational coding systems (pp. 243-256). Mahwah, NJ: Erlbaum.

Cramer, D. (2000). Relationship satisfaction and conflict style in romantic relationships. Journal of Psychology, 134(3), 337.

Crowley, A. K. (2008). The relationship of adult attachment style and interactive conflict styles to marital satisfaction. Dissertation Abstracts International Section A, 68, 3744.

Davis, S. Y., Sandberg, J. G., Bradford, A. B., \& Larson, J. H. (2016). Gender differences in couple attachment behaviors as predictors of dietary habits and physical activity levels. Journal of Health Psychology, 21(12), 3048-3059. doi:10.1177/1359105315592049

DeWall, C. N., Lambert, N. M., Slotter, E. B., Pond, R. J., Deckman, T., Finkel, E. J., \& ... Fincham, F. D. (2011). So far away from one's partner, yet so close to romantic alternatives: Avoidant attachment, interest in alternatives, and infidelity. Journal of Personality and Social Psychology, 101(6), 1302-1316. doi:10.1037/a0025497.

Dobry, S., Bradford, A. B., Sandberg, J. G., \& Coyne, S. M. (under review). The moderating effect of attachment behaviors on the association between video game use and relationship outcomes.

Drean, L., Bradford, A. B., Sandberg, J. G., \& Johnson, L. N. (under review). Attachment behaviors as a mediator of the relationship between approval and relationship quality.

Driver, J., Tabares, A., Shapiro, A. F., \& Gottman, J. M. (2012). Couple interaction in happy and unhappy marriages: Gottman laboratory studies. In F. Walsh (Ed.), Normal family processes: Growing diversity and complexity, 4th ed (pp. 57-77). New York, NY, US: Guilford Press. 
Elkins, D. N. (2016). Attachment theory and social relationships research: The power of human connection and social interaction. In, The human elements of psychotherapy: $A$ nonmedical model of emotional healing (pp. 33-51). Washington, DC, US: American Psychological Association. doi:10.1037/14751-003.

Feeney, J. A. (2016) Adult romantic attachment: Developments in the study of couple relationships. In J. Cassidy \& P. Shaver (Eds.), Handbook of attachment: Theory, research, and clinical applications ( $3^{\text {rd }}$ ed., 435- 463). New York: Guilford Press.

Finkel, E. J., Slotter, E. B., Luchies, L. B., Walton, G. M., \& Gross, J. J. (2013). A brief intervention to promote conflict reappraisal preserves marital quality over time. Psychological Science, 24(8), 1595-1601. doi:10.1177/0956797612474938

Furrow, J. L., Edwards, S. A., Choi, Y., \& Bradley, B. (2012). Therapist presence in emotionally focused couple therapy blamer softening events: Promoting change through emotional experience. Journal of Marital and Family Therapy, 38(Suppl 1), 39-49.

doi:10.1111/j.1752-0606.2012.00293.x

Gaines, S., Reis, H., Summers, S., Rusbult, C., Cox, C., Wexler, M., Marelich, W., \& Kurland, G. (1997). Impact of attachment style on reactions to accommodative dilemmas in close relationships. Personal Relationships, 4, 93-113.

Givertz, M., Woszidlo, A., Segrin, C., \& Knutson, K. (2013). Direct and indirect effects of attachment orientation on relationship quality and loneliness in married couples. Journal of Social and Personal Relationships, 30(8), 1096-1120.

doi:10.1177/0265407513482445. 
Goldstein, S., Chesir-Teran, D., \& McFaul, A. (2008). Profiles and correlates of relational aggression in young adults' romantic relationships. Journal of Youth \& Adolescence, 37, 251.

Gordon, A. M., \& Chen, S. (2016). Do you get where I'm coming from?: Perceived understanding buffers against the negative impact of conflict on relationship satisfaction. Journal of Personality and Social Psychology, 110(2), 239-260.

doi:10.1037/pspi0000039

Gottman, J. M. (1993). A theory of marital dissolution and stability. Journal of Family Psychology, 7, 57-75.

Gottman, J. M. (1993). The roles of conflict engagement, escalation, and avoidance in marital interaction: A longitudinal view of five types of couples. Journal of Consulting and Clinical Psychology, 61, 6-15.

Gottman, J. M. (1994). What predicts divorce?: The relationship between marital processes and marital outcomes. Hillsdale, NJ: Erlbaum.

Gottman, J. M. (1999). The marriage clinic: A scientifically based marital therapy. New York: W. W. Norton.

Gottman, J. M., \& Levenson, R.W. (2000). The timing of divorce: Predicting when a couple will divorce over a 14-year period. Journal of Marriage and the Family, 62, 737-745.

Greeff, A. P., \& de Bruyne, T. (2000). Conflict management style and marital satisfaction. Journal of Sex \& Marital Therapy, 26(4), 321-334. doi:10.1080/009262300438724

Greenman, P. S., Faller, G., \& Johnson, S. M. (2012). Finding the words: Working with men in emotionally focused therapy (EFT) for couples. In D. S. Shepard \& M. Harway (Eds.), Engaging men in couples therapy (pp. 129-151). New York, NY: Routledge. 
Halford, W. K. (2011). Marriage and relationship education: What works and how to provide it. New York: The Guilford Press.

Hanzal, A., \& Segrin, C. (2009). The role of conflict resolution styles in mediating the relationship between enduring vulnerabilities and marital quality. Journal of Family Communication, 9(3), 150-169. doi:10.1080/15267430902945612

Hazan, C., \& Shaver, P. (1987). Romantic love conceptualized as an attachment process. Journal of Personality and Social Psychology, 52(3), 511-524. doi:10.1037/0022-3514.52.3.511.

Henning, K., Jones, A. R., \& Holdford, R. (2005). “I didn't do it, but if I did I had a good reason": Minimization, denial, and attributions of blame among male and female domestic violence offenders. Journal of Family Violence, 20(3), 131-139. doi:10.1007/s10896-005-3647-8

Holman, T.B., \& Jarvis, M. O. (2003). Hostile, volatile, avoiding, and validating couple-conflict types: An investigation of Gottman's couple-conflict types. Personal Relationships, 10, $267-282$.

Holmes, J. (2014). John Bowlby and attachment theory., 2nd ed. New York, NY, US: Routledge/Taylor \& Francis Group.

Hu, L. T., \& Bentler, P. M. (1999). Cutoff criteria for fit indexes in covariance structure analysis: Conventional criteria versus new alternatives. Structural Equation Modeling: A Multidisciplinary Journal, 6(1), 1-55. http://dx.doi.org/10.1080/10705519909540118.

Johnson, L. N., Tambling, R. B., Mennenga, K. D., Ketring, S. A., Oka, M., Anderson, S. R., \& Miller, R. B. (2016). Examining attachment avoidance and attachment anxiety across eight sessions of couple therapy. Journal of Marital and Family Therapy, 42(2), 195 212. doi:10.1111/jmft.12136. 
Johnson, S. M. (2004). The practice of emotionally focused couple therapy: Creating connection (2nd ed.). New York: Brunner-Routledge.

Johnson, S. M., \& Greenman, P. S. (2006). The path to a secure bond: Emotionally focused couple therapy. Journal of Clinical Psychology, 62(5), 597-609.

Kashy, D. A., \& Kenny, D. A. (2000). The analysis of data from dyads and groups. In H. T. Reis \& C. M. Judd (Eds.), Handbook of research methods in social and personality psychology (pp. 451-477). New York, NY, US: Cambridge University Press.

Kilpatrick, S., Bissonnette, V., \& Rusbult, C. (2002). Empathic accuracy and accommodative behavior among newly married couples. Personal Relationships, 9, 369-393.

Kline, R. B. (2005). Principles and practice of structural equation modeling. New York, NY: Guilford Press.

Knapp, D. J., Sandberg, J. G., Novak, J., \& Larson, J. H. (2015). The mediating role of attachment behaviors on the relationship between family-of-origin and couple communication: Implications for couples therapy. Journal of Couple \& Relationship Therapy, 14(1), 17-38. doi:10.1080/15332691.2014.953650.

Ledbetter, C. A. (2016). Romantic relationships: Adult attachment styles and conflict patterns. Dissertation Abstracts International, 77.

Liu, Z., Cui, M., \& Han, Y. (2014). Adult attachment, conflict resolution behaviors and close relationship satisfaction in young couples. Chinese Mental Health Journal, 28(8), $597-$ 601.

Mackey, R. A., \& O'Brien, B. A. (1998). Marital conflict management: Gender and ethnic differences. Social Work, 43(2), 128-141. doi:10.1093/sw/43.2.128 
Markman, H. (1991). Constructive marital conflict is not an oxymoron. Behavioral Assessment, 13, 83-96.

Meredith, W., \& Teresi, J. A. (2006). An essay on measurement and factorial invariance. Medical Care, 44(11, Suppl 3), S69-S77. doi:10.1097/01.mlr.0000245438.73837.89

Mikulincer, M., \& Goodman, G.S. (2006). Dynamics of romantic love: Attachment, caregiving and sex. New York, NY: Guilford Press.

Mikulincer, M., \& Shaver, P. R. (2007). Attachment in adulthood: Structure, dynamics, and change. (pp. 251-323). New York, NY, US: Guilford Press.

Moser, M. B., Johnson, S. M., Dalgleish, T. L., Lafontaine, M., Wiebe, S. A., \& Tasca, G. A. (2016). Changes in relationship-specific attachment in emotionally focused couple therapy. Journal of Marital and Family Therapy, 42(2), 231-245. doi:10.1111/jmft.12139.

Oka, M., Sandberg, J. G., Bradford, A. B., \& Brown, A. (2014). Insecure attachment behavior and partner violence: Incorporating couple perceptions of insecure attachment and relational aggression. Journal of Marital and Family Therapy, 40(4), 412-429. doi:10.1111/jmft.12079.

Patrick, H., Knee, C., Canevello, A., et al. (2007). The role of need fulfillment in relationship functioning and well-being: A self-determination theory perspective. Journal of Personality and Social Psychology, 92(3), 434-457. 
Perrone-McGovern, K. M., Oliveira-Silva, P., Simon-Dack, S., Lefdahl-Davis, E., Adams, D., McConnell, J., \& ... Gonçalves, Ó. F. (2014). Effects of empathy and conflict resolution strategies on psychophysiological arousal and satisfaction in romantic relationships. Applied Psychophysiology and Biofeedback, 39(1), 19-25. doi:10.1007/s10484-013-92372

Pietromonaco, P., Greenwood, D., \& Feldman Barrett, L. (2004). In W. S. Rholes \& J. A. Simpson (Eds.), Conflict in adult close relationships: An attachment perspective (pp. 267-299). New York: Guilford Press.

Pistole, M. C. (1989). Attachment in adult romantic relationships: Style of conflict resolution and relationship satisfaction. Journal of Social and Personal Relationships, 6(4), 505-512. doi:10.1177/0265407589064008.

Prager, K. J., Shirvani, F., Poucher, J., Cavallin, G., Truong, M., \& Garcia, J. J. (2015). Recovery from conflict and revival of intimacy in cohabiting couples. Personal Relationships, 22(2), 308-334. doi:10.1111/pere.12082

Sandberg, J. G., Bradford, A. B., \& Brown, A. P. (2015). Differentiating between attachment styles and behaviors and their association with marital quality. Family Process, 56(2), 518-531. doi:10.1111/famp.12186.

Sandberg, J. G., Busby, D. M., Johnson, S. M., \& Yoshida, K. (2012). The brief accessibility, responsiveness, and engagement (BARE) scale: A tool for measuring attachment behavior in couple relationships. Family Process, 51(4), 512-526. doi:10.1111/j.15455300.2012.01422.x. 
Schade, L. C., Sandberg, J. G., Bradford, A., Harper, J. M., Holt-Lunstad, J., \& Miller, R. B. (2015). A longitudinal view of the association between therapist warmth and couples' in-session process: An observational pilot study of emotionally focused couples therapy. Journal of Marital and Family Therapy, 41(3), 292-307. doi:10.1111/jmft.12076

Scheeren, P., de Andrade Vieira, R. V., Goulart, V. R., \& Wagner, A. (2014). Marital quality and attachment: The mediator role of conflict resolution styles. Paidéia, 24(58), 177-186. doi:10.1590/1982-43272458201405.

Seedall, R.B. \& Wampler, K.S. (2013). An attachment primer for couple therapists: Research and clinical implications. Journal of Marital and Family Therapy, 39, 427-440. doi:10.1111/jmft.12024

Segrin, C., Hanzal, A., \& Domschke, T. J. (2009). Accuracy and bias in newlywed couples' perceptions of conflict styles and the association with marital satisfaction. Communication Monographs, 76(2), 207-233. doi:10.1080/03637750902828404.

Shi, L. (2003). The association between adult attachment styles and conflict resolution in romantic relationships. American Journal of Family Therapy, 31(3), 143-157. doi:10.1080/01926180301120.

Shockley-Zalabak, P. S., \& Morley, D. D. (1984). Sex differences in conflict style preferences. Communication Research Reports, 1(1), 28-32.

Sillars, A., Roberts, L. J., Leonard, K. E., \& Dun, T. (2000). Cognition during marital conflict: The relationship of thought and talk. Journal of Social and Personal Relationships, 17, 479-502.

Simpson, J. (1990). Influence of attachment styles on romantic relationships. Journal of Personality and Social Psychology, 59(5), 971-980. 
Simpson, J. A., Rholes, W. S., \& Phillips, D. (1996). Conflict in close relationships: An attachment perspective. Journal of Personality and Social Psychology, 71(5), 899-914. doi:10.1037/0022-3514.71.5.899.

Stackert, R. A., \& Bursik, K. (2003). Why am I unsatisfied? Adult attachment style, gendered irrational relationship beliefs, and young adult romantic relationship satisfaction. Personality and Individual Differences, 34(8), 1419-1429. doi:10.1016/S01918869(02)00124-1.

Stith, S. M., McCollum, E. E., \& Rosen, K. H. (2011). Session 5: Escalation and negotiated timeout. In S. M. Stith, E. E. McCollum \& K. H. Rosen (Eds.), Couples therapy for domestic violence: Finding safe solutions (pp. 87-108). Washington, DC: American Psychological Association.

Sullaway, M., \& Christensen, A. (1983). Assessment of dysfunctional interaction patterns in couples. Journal of Marriage and the Family, 45, 653-660.

Tucker, J., \& Anders, S. (1999). Attachment style, interpersonal perception accuracy, and relationship satisfaction in dating couples. Personality and Social Psychology Bulletin, 25(4), 403-412.

Wanic, R., \& Kulik, J. (2011). Toward an understanding of gender differences in the impact of marital conflict on health. Sex Roles, 65(5-6), 297-312. doi:10.1007/s11199-011-9968-6

Watzlawick, P., Bavelas, J. B., \& Jackson, D. D. (1967). Pragmatics of human communication: A study of interactional patterns, pathologies, and paradoxes. New York: W.W. Norton \& Company. 
Wheeler, L. A., Updegraff, K. A., \& Thayer, S. M. (2010). Conflict resolution in Mexicanorigin couples: Culture, gender, and marital quality. Journal of Marriage and Family, 72(4), 991-1005. doi:10.1111/j.1741-3737.2010.00744.x.

Wilson, J. B. (2011). Exploring the influence of dyadic adult attachment on physical, sexual, and relational aggression within romantic relationships (Unpublished dissertation). Oklahoma State University, Stillwater, OK.

Windle, C. R., \& Smith, D. A. (2009). Withdrawal moderates the association between husband gender role conflict and wife marital adjustment. Psychology of Men \& Masculinity, 10(4), 245-260. doi:10.1037/a0016757

Wittenborn, A. K., Dolbin-MacNab, M. L., \& Keiley, M. K. (2013). Dyadic research in marriage and family therapy: Methodological considerations. Journal of Marital and Family Therapy, 39(1), 5-16. doi:10.1111/j.1752-0606.2012.00306.x

Worley, T. R., \& Samp, J. A. (2016). Gendered associations of decision-making power, topic avoidance, and relational satisfaction: A differential influence model. Communication Reports, 29(1), 1-12. doi:10.1080/08934215.2015.1025988 
Figure 1: APIM Model of Conflict Styles and Attachment Behaviors on Relationship Quality

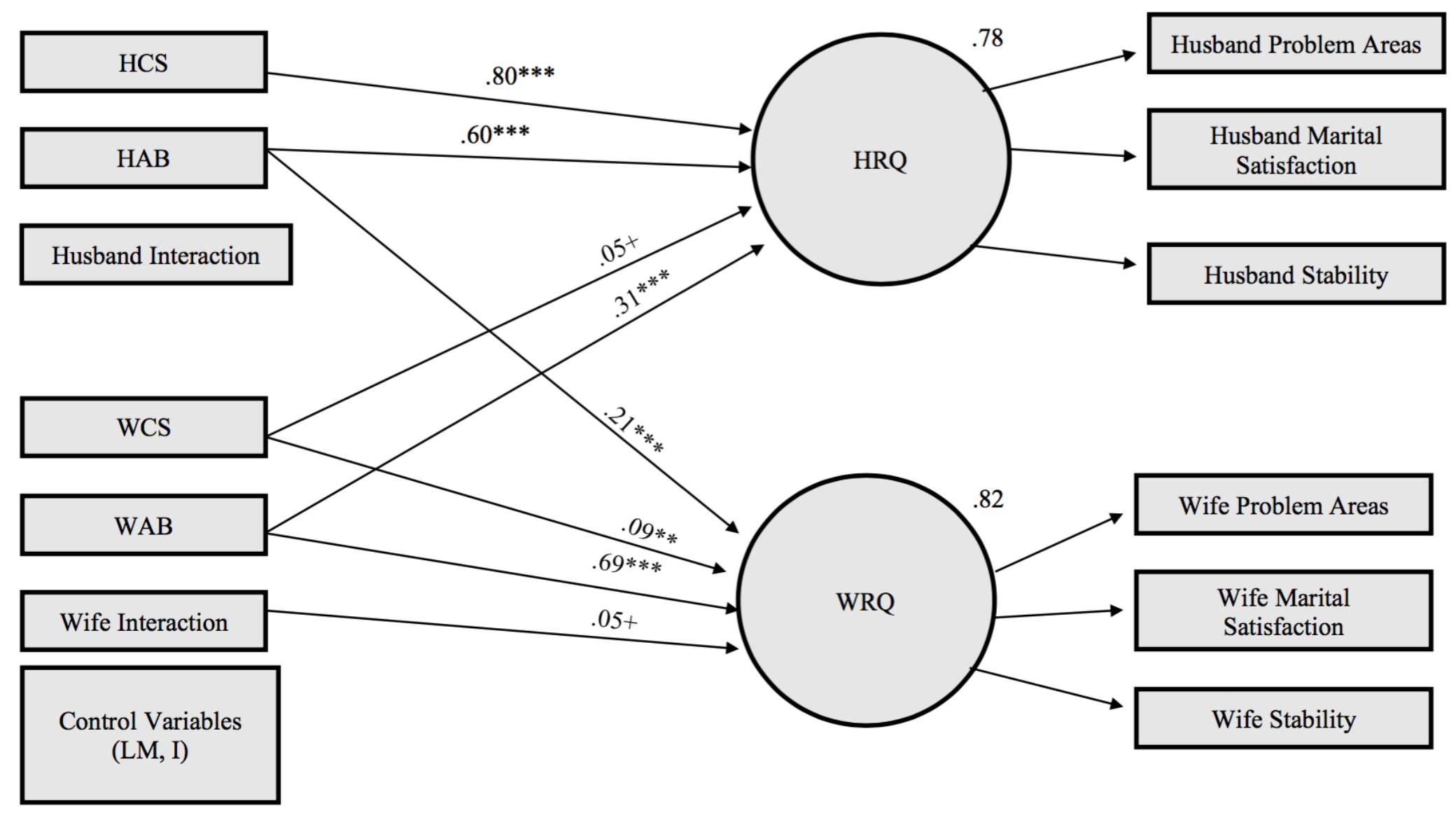

Note: Standardized Regression Weights $=$ reported CVD $\left(\left(X^{2}=181.06, p=7.000(\mathrm{df}=41, \mathrm{~N}=591) \mathrm{CFI}=.969\right.\right.$, TLI $=.932$, RMSEA $=.076).) .+\mathrm{p}<.10 ; * \mathrm{p}<.05 ; * * \mathrm{p}<01 ; * * * \mathrm{p}<.001$

Key: (H) Husband, (W) Wife, (CS) Conflict Style, (AB) Attachment Behaviors, (RQ) Relationship, Quality, (LR) Length of Marriage, (I) Income 
Figure 2.

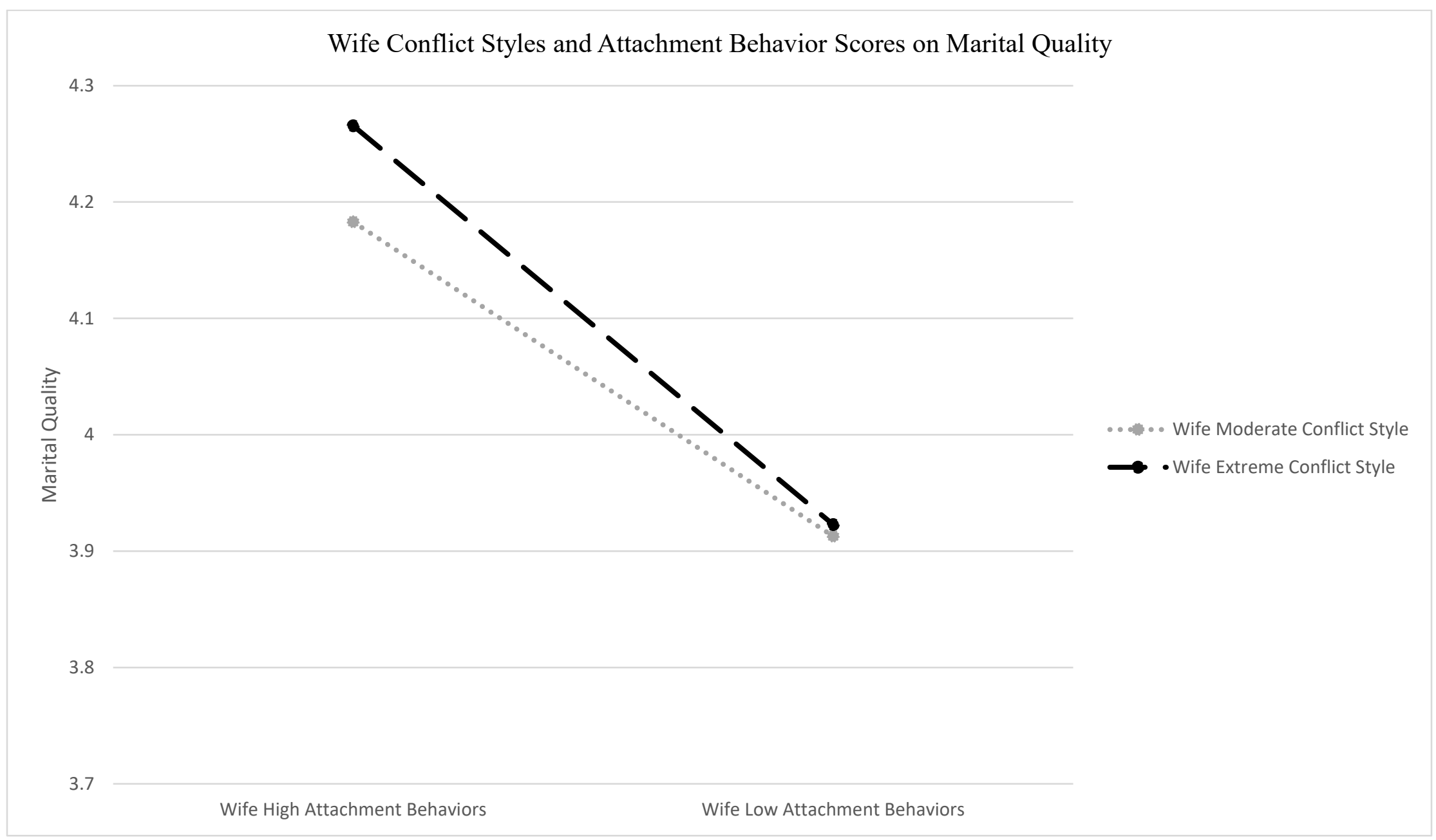


Table 1 - Descriptive Statistics of Study Variables

\begin{tabular}{|c|c|c|c|}
\hline Variables & $\mathrm{N}$ & Mean & SD \\
\hline \multicolumn{4}{|l|}{ Males } \\
\hline \multicolumn{4}{|l|}{ Relationship Quality: } \\
\hline Relationship Stability & 591 & 4.21 & .772 \\
\hline Relationship Satisfaction & 591 & 3.68 & .88 \\
\hline Problem Areas & 591 & 3.84 & .52 \\
\hline $\begin{array}{l}\text { Attachment Behaviors } \\
\text { (Self-Rated) }\end{array}$ & 589 & 23.7 & 3.68 \\
\hline Conflict Style: & & Frequency & Percent \\
\hline Aversive Conflict Style & 591 & 183 & 30.9 \\
\hline Measured Conflict Style & 591 & 408 & 69 \\
\hline \multicolumn{4}{|l|}{ Females } \\
\hline Relationship Quality: & & & \\
\hline Relationship Stability & 591 & 4.13 & .862 \\
\hline Relationship Satisfaction & 591 & 3.59 & 1 \\
\hline Problem Areas & 591 & 3.81 & .59 \\
\hline $\begin{array}{l}\text { Attachment Behaviors } \\
\text { (Self-Rated) }\end{array}$ & 591 & 24.8 & 3.67 \\
\hline Conflict Style: & & Frequency & Percent \\
\hline Aversive Conflict Style & 591 & 168 & 28.5 \\
\hline Measured Conflict Style & 591 & 423 & 71.6 \\
\hline
\end{tabular}


Table 2 - Correlation Table

\begin{tabular}{llllllllllll}
\hline Variables & 1 & 2 & 3 & 4 & 5 & 6 & 7 & 8 & 9 \\
\hline
\end{tabular}

1. Relationship Satisfaction

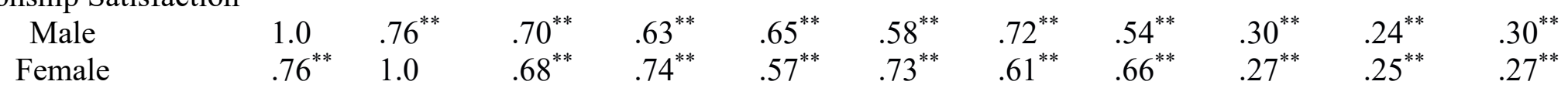

2. Relationship Stability

$\begin{array}{llllllllllll}\text { Male } & .70^{* *} & .68^{* *} & 1.0 & .80^{* *} & .59^{* *} & .56^{* *} & .56^{* *} & .47^{* *} & .26^{* *} & .22^{* *} & .26^{* *} \\ \begin{array}{l}\text { Female } \\ \text { blem Areas }\end{array} & .63^{* *} & .74^{* *} & .80^{* *} & 1.0 & .52^{* *} & .64^{* *} & .48^{* *} & .57^{* *} & .24^{* *} & .24^{* *} & .24^{* *} \\ \text { Male } & & & & & & & & & & & \\ \text { Female } & .65^{* *} & .57^{* *} & .59^{* *} & .52^{* *} & 1.0 & .65^{* *} & .62^{* *} & .46^{* *} & .20^{* *} & .24^{* *} & .20^{* *} \\ & .58^{* *} & .73^{* *} & .56^{* *} & .64^{* *} & .65^{* *} & 1.0 & .47^{* *} & .60^{* *} & .18^{* *} & .22^{* *} & .18^{* *}\end{array}$

3. Attachment Behaviors

(Self-Rated)

$\begin{array}{cccccccccccc}\text { Male } & .72^{* *} & .61^{* *} & .56^{* *} & .48^{* *} & .62^{* *} & .47^{* *} & 1.0 & .46^{* *} & .33^{* *} & .15^{* *} & .33^{* *} \\ \text { Female } & .54^{* *} & .66^{* *} & .47^{* *} & .57^{* *} & .46^{* *} & .60^{* *} & .46^{* *} & 1.0 & .13^{* *} & .27^{* *} & .13^{* *} \\ \text { CS } & & & & & & & & & & & \\ \text { CS CS } & .30^{* *} & .27^{* *} & .26^{* *} & .24^{* *} & .20^{* *} & .18^{* *} & .33^{* *} & .13^{* *} & 1.0 & .06 & 1.0^{* *} \\ & .24^{* *} & .25^{* *} & .22^{* *} & .24^{* *} & .24^{* *} & .22^{* *} & .15^{* *} & .27^{* *} & .06 & 1.0 & .06\end{array}$

Aversive CS

Measured CS

**. Correlation is significant at the 0.01 level 
Table 3

\begin{tabular}{|c|c|}
\hline \multicolumn{2}{|c|}{ Husband and Wife Marital Quality Factor Loadings } \\
\hline \multicolumn{2}{|l|}{ Husband } \\
\hline Problem Areas & 0.79 \\
\hline Relationship Satisfaction & 0.9 \\
\hline Stability & 0.69 \\
\hline \multicolumn{2}{|l|}{ Wife } \\
\hline Problem Areas & 0.76 \\
\hline Relationship Satisfaction & 0.89 \\
\hline Stability & 0.66 \\
\hline
\end{tabular}

